\title{
Stochastic Lot-Sizing under Carbon Emission Control for Profit Optimisation in MTO Manufacturing
}

\author{
A. Qiao, S.H. Choi , X.J. Wang and Y.C. Zhao \\ Department of Industrial and Manufacturing Systems Engineering, the University of Hong Kong, Hong Kong
}

\begin{abstract}
Aggravating global warming has heightened the imminent need by the world to step up forceful efforts on curbing emission of greenhouse gases. Although manufacturing is a major resource of carbon emission, few research works have studied the impacts of carbon constraints on manufacturing, leading to environmentally unsustainable production strategies and operations. This paper incorporates carbon emission management into production planning for make-to-order (MTO) manufacturing. This paper proposes a model that solves lot-sizing problems to maximise profits under carbon emission caps. The model adopts stochastic interarrival times for customer orders to enhance the practicality of the results for real-world manufacturing. Numerical experiments show that reducing carbon emission undercuts short-term profits of a company. However, it is conducive to the company's market image as being socially responsible which would attract more customers who concern about environmental protection. Hence, reducing carbon emission in manufacturing is beneficial to long-term profitability and sustainability. The results provide managerial insights into manufacture operations for balancing profitability and carbon control.
\end{abstract}

\section{Introduction}

In recent decades, global warming has been aggravated due to excessive carbon emission from human activities. World governments are under huge pressure to mitigate the harmful impacts on the environment by tightening regulations on carbon emission. One of the most significant programs for carbon emission control is the United Nations Framework Convention on Climate Change held by 154 nations in 1992. In 2015, the Paris Agreement was concluded in the 21st Session of the Conference of the Parties, which elevated the international corporation in carbon emission management to a new stage [1].

A major source of carbon emission is industrial production, since it consumes huge amounts of materials and energy and releases much wastes. Besides the traditional make-to-stock (MTO) production mode that maintains inventory for incoming orders, more companies start to focus on the make-to-order (MTO) mode that produces products only after receiving customer orders, which is considered conducive to carbon emission management by applying suitable emission constraints.

Many researchers have contributed to the study of carbon emission management. Sarkis et al. conducted a review of organizational theoretic literature, while Brandenburg et al. conducted a review about the quantitative models that have been used in sustainable supply chain management [2], [3]. Accenture examined supply chain information about the risks and opportunities related to climate change in its supply chain report [4]. Besides, Govindan et al. studied the recent status and opportunities for the green supply chain management [5].

Although manufacturing is a major source of GHGs, only some researchers have attempted to incorporate carbon control into optimization of production operations. Absi et al. provided production planning considering carbon emission policies and Chen et al. worked on the economic order quantity (EOQ) model considering the carbon emission in production cost. [6], [7]. Among the above works reviewed, few have focused on MTO.

To mitigate the research gap, this paper incorporates carbon control in stochastic lot-sizing optimization for MTO manufacturing. It proposes a model for optimal lot size that maximises the profit without emitting carbon more than a given cap during the production process. To enhance its practicality for real-world manufacturing, the model adopts interarrival times with stochastic distributions for customer orders. Numerical experiments are conducted and the result helps manufacturers balance short-term profitability and carbon control, which is vital to long-term profitability and business sustainability.

In the remainder of this paper, Section 2 elaborates the production planning problems and the mathematical formulas in detail. Section 3 conducts a numerical case study and presents the analytical results, while section 4 draws conclusions.

\section{Production model formulation}




\subsection{The stochastic MTO production system}

Fig. 1 shows the production system for single-product MTO manufacturing, in which independent customer orders arrive at stochastic interarrival times. When orders accumulate to a given size $Q$, they are gathered and transferred in a batch to the setup stage for the initial processing. These batches are then moved to the processing stage to be manufactured one by one. When the product for an order is completed, it is directly delivered to the end customer without waiting for other orders in the same batch. The lot size $Q$ is crucial to the performance of such a production system. While a small lot size causes frequent setups and hence shop floor nervousness, a large one leads to high work-in-process (WIP) inventory which increases not only costs but also carbon emission during storage.

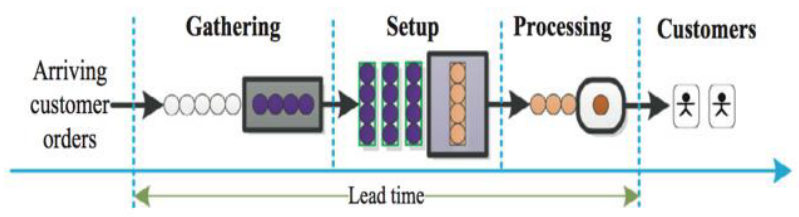

Figure 1. Stochastic MTO production system

\subsection{The proposed model}

The proposed model therefore aims to solve for an optimal lot size that maximises the profit of products while limiting the total carbon emission during production below a given carbon cap, which is deemed by governments as an effective way to control carbon emission by individual manufacturers. Governments generally set carbon caps for manufacturers smaller than their annual emissions. If a manufacturer does not exceed its carbon cap, it pays no cost; otherwise, it has to pay extra tax or purchase carbon quota for its excessive emission. Hence, the proposed model supposes that the manufacturer will adjust its lot size $Q$ to reduce carbon emission to avoid extra cost due to excessive emission. Other assumptions made for the model are:

(1) Orders are independent so that all orders come in stochastically with an independent and stable increment.

(2) All machines are independent, and machine breakdown is not considered.

(3) Orders are processed based on the first-come-firstserve principle.

(4) Each order includes only one single product.

(5) The product price is exogenous, and the manufacturer has no influence on the product price.

(6) The decision variables and stated indexes do not influence the stochastic process.

\section{Notations}

$\begin{array}{ll}Q & \text { Lot size } \\ R & \text { Operational profit } \\ D & \text { Uncertain marketing demand } \\ \gamma & \text { Unit sales price } \\ C_{V} & \text { Variable costs } \\ C_{F} & \text { Fixed costs }\end{array}$

\begin{tabular}{cl}
\hline$s$ & Unit setup cost \\
$h$ & Unit WIP carrying cost \\
$W$ & Total work flow time \\
$X_{i}$ & Interarrival time of the $i^{\text {th }}$ order, all $X_{i}$ 's are \\
& independent and identically distributed (IID) \\
$Y_{i}$ & Setup time of the $i^{\text {th }}$ batch, all $Y_{i}$ 's are IID \\
$Z_{i}$ & Processing time of the $i^{t h}$ order, all $Z_{i}$ 's are IID \\
$X^{b}$ & Interarrival times of batches for the assumed \\
& GI/G/1 queuing model \\
$T_{b}$ & Service time for the assumed GI/G/1 queuing \\
$\tau$ & Mean setup time \\
$\mu$ & Mean processing rate \\
$e_{m}$ & Carbon emission from manufacturing \\
$e_{W I P}$ & Carbon emission from WIP inventories \\
$M$ & Emission cap \\
\hline
\end{tabular}

\subsubsection{Benchmark model without carbon emission constraint}

This research first derives the proposed model for MTO production without considering carbon emission as a benchmark against production under carbon emission constraint. The operational profit $\mathrm{R}$ is formulated as:

$$
R=D \gamma-C_{V}-C_{F}
$$

with

$$
C_{V}=D(s / Q+E(W) h+\omega)
$$

where $\omega$ represents all the unit variable costs irrelevant to the product lot size and the expected leading time, and $E(W)$ means the mean WIP inventory time.

To solve $E(W)$, all the involved random variables are characterized based on the expected values and variances without assumptions on the distribution. Based on Fig. 1, the total work flow time is:

$$
E(W)=E\left(W_{q g}\right)+E\left(W_{g}\right)+E\left(W_{q s}\right)+E\left(W_{s}\right)+E\left(W_{q p}\right)+E\left(W_{p}\right)
$$

When an order is received, it is immediately gathered into batches without waiting, so that queuing time for gathering $E\left(W_{q g}\right)=0$. The gathering time for the $i^{t h}$ order is the time that it waits for the remaining $Q-i$ orders to be gathered with itself into a batch, i.e.,

$$
E\left(W_{g}\right)=E_{i}\left(E\left(W_{g} \mid i\right)=(Q-1) / D\right.
$$

To calculate queuing time for setup $E\left(W_{q s}\right)$, the setup and processing stages may be simplified as a $\mathrm{GI} / \mathrm{G} / 1$ queuing model. It is similar to the production situation, except the processing time is overestimated, which will not affect the $W_{q s}$. Based on the equations for $\mathrm{GI} / \mathrm{G} / 1$ model,

$$
\begin{gathered}
E\left(W_{q s}\right)=\left[\operatorname{Var}\left(X^{b}\right)+\operatorname{Var}\left(T^{b}\right)\right] / 2\left[E\left(X^{b}\right)-E\left(T^{b}\right)\right] \\
E\left(X^{b}\right)=Q / D, \operatorname{Var}\left(X^{b}\right)=Q \sigma_{X}^{2}, \\
E\left(T^{b}\right)=\tau+Q / \mu, \\
\operatorname{Var}\left(T^{b}\right)=\sigma_{Y}^{2}+Q \sigma_{Z}^{2}
\end{gathered}
$$


With $\rho=E\left(T^{b}\right) / E\left(X^{b}\right)$, where $\sigma_{x}{ }^{2}, \sigma_{Y}{ }^{2}, \sigma_{Z}{ }^{2}$ represent the variance of interarrival times of orders, setup and processing correspondingly.

The queuing time for processing is:

$$
\begin{gathered}
E\left(W_{q p} \mid i\right)=E\left(Z_{1}+Z_{2}+\ldots Z_{i-1} \mid i\right)=(i-1) / \mu \\
E\left(W_{q p}\right)=E_{i}\left(E\left(W_{q p} \mid i\right)\right)=(Q-1) / 2 \mu
\end{gathered}
$$

Besides, it has already been obtained that setup and process time are:

$$
E\left(W_{s}\right)=\tau, E\left(W_{p}\right)=1 / \mu
$$
yields

By substituting $E\left(W_{q g}\right)=0$, (4), (5), (8), and (9) into (3)

$$
E(W)=\frac{Q-1}{2 D}+\frac{Q\left(\sigma_{X}^{2}+\sigma_{Z}^{2}\right)+\sigma_{Y}^{2}}{2\left[Q\left(\frac{1}{D}-\frac{1}{\mu}\right)-\tau\right]}+\frac{Q+1}{2 \mu}+\tau
$$

In the real production situation, the lot size $Q$ may not be less than one and the traffic intensity $\rho$ has to be less than $100 \%$ for a realistic queuing case, so that:

$$
Q \geq 1, \quad \rho<100 \%
$$

\subsubsection{Model with carbon emission constraint}

A carbon cap is used as a constraint in the proposed model to restrict the total amount of carbon emission in the production process below the carbon cap when maximizing the profit. The production process in Figure 1 includes two major carbon emission sources, namely the manufacturing process and the WIP inventory.

Carbon emission from manufacturing is mainly due to the fossil fuel and electricity used to operate vehicles and machines and carbon emission from WIP inventory is incurred during storage and transfer of semi-finished products. Besides, WIP inventory is related to demand, as well as to the holding time $E(W)$. Hence the total carbon emission is:

$$
e=e_{m}+e_{W T P}=k_{0}+D k_{1}+g_{0}+g_{1} D E(W)
$$

where $k_{0}$ means the fixed carbon emission factor for the carbon emission by vehicles driven empty and machines run without production, while $k_{1}$ means the variable carbon emission factor, calculating the surplus marginal carbon emission for each one more product produced. $g_{0}$ and $g_{l}$ are the fixed and variable carbon emission factors for the WIP inventory correspondingly.

Consequently, the total carbon emission $e$ must be no more than the allowable emission cap M, i.e.

$$
e=e_{m}+e_{W I P} \leq M
$$

\subsubsection{Propositions}

Based on the above formulations, propositions are summarized, but due to the space limitation, the propositions are listed without detailed illustration as below.
Proposition 1. The operational profit $R$ in the benchmark model is concave in its domain.

Proposition 2. The optimal lot size $Q^{*}$ that maximises the operational profit $R$ for the benchmark model must satisfy the following quartic equation:

$\frac{A B^{2} h}{2} Q^{4}-A B h \tau Q^{3}+\left(\frac{A h \tau^{2}}{2}-\frac{C h}{2}-s B^{2}\right) Q^{2}+2 B s \tau Q-s \tau^{2}=0$

with $A=\frac{1}{D}+\frac{1}{\mu}, B=\frac{1}{D}-\frac{1}{\mu}$, and $C=\left(\sigma_{X}^{2}+\sigma_{Z}^{2}\right) \tau+\left(\frac{1}{D}-\frac{1}{\mu}\right) \sigma_{Y}^{2}$

Proposition 3. There exists only one optimal lot size $Q^{*}$ for the benchmark model.

Proposition 4. For the benchmark production model the profit curve is (1) positively sloped in the interval $\left[Q_{\min }, Q^{*}\right] ;(2)$ negatively sloped in the interval $\left[Q^{*},+\infty\right]$, where $Q_{\min }=\max \{\tau /(1 / D-1 / \mu), 1\}$.

Proposition 5. The carbon emission function $e$ is convex in terms of $Q$ in its domain.

Proposition 6. Under the carbon emission constraint, there are three different situations for $Q^{*}$, as follows:

a. when $Q^{e, 1} \leq Q^{*} \leq Q^{e, 2}$, the optimal lot sizing solution is still $Q^{*}$

b. when $Q^{*} \leq Q^{e, I}$, the optimal solution is $Q^{e, I}$ with profit decreased

c. when $Q^{*} \geq Q^{e, 2}$, the optimal solution is $Q^{e, 2}$ with profit decreased

\section{Numerical case study}

Numerical experiments are conducted in this section to validate the proposed MTO manufacturing optimization model. The theoretical propositions proven in the last section are used to determine the globally optimal solution. In these numerical examples, the data for the random variables involved are based on the heat treatment industry case study by Lambrecht, Chen, and Vandaele [8], as follows:

Demand ratio $1 / D=1.0000$ minutes, variance of interarrival times of orders ${\sigma_{X}}^{2}=0.5000$, mean setup time $\tau=10.0000$ minutes, variance of setup times $\sigma_{Y}^{2}$ $=10.0000$, mean process time $1 / \mu=0.5000$ minutes, variance of processing times $\sigma_{Z}^{2}=0.0625$.

All the other parameters pertinent to carbon emission, costs, and assets can be collected from the manufacturer's managerial accounting systems [9]. Hence these data are:

Fixed carbon emission factor in manufacturing $k_{0}=2$ ton/year, variable carbon emission factor in manufacturing $k_{l}=0.02 \mathrm{~kg}$, fixed carbon emission factor in WIP inventories $g_{0}=3$ ton/year, variable carbon emission factor in WIP inventories $g_{I}=0.01 \mathrm{~kg} / \mathrm{min}$, sum of other variable costs $\omega=\$ 2.5$, unit setup cost $s=\$ 1200$, unit WIP cost $h=\$ 1.5$, fixed cost $C_{F}=\$ 2.0$ million, unit sales price $\gamma=\$ 150$.

Since the carbon cap is usually annually based, the case study is set as a 2-year production plan to observe the influence of carbon cap onto the production performance. The production line operates 12 months per year, 20 days per month, and 8 hours per day, so that the total demand for 2 years is 


$$
D_{\text {Total }}=D \times 60 \times 8 \times 20 \times 12 \times 2=230400 \text {. }
$$

\subsection{Benchmark model}

By substituting the above data into (19), the optimal lot size $Q^{*}$ for the benchmark mode is 34.9502 , the expected total work time is 37.9645 mins, the maximal profit is $\$ 5.4$ million per year, and the total carbon emission is 51 tons per year.

Based on the Fig. 2, it can be observed that the minimal value for $E(W)$ is 33.38 , which limits the value of carbon emission cap $M$ to be no less than 46 tons to get the real number solution for $Q^{e, 1}$ and $Q^{e, 2}$.

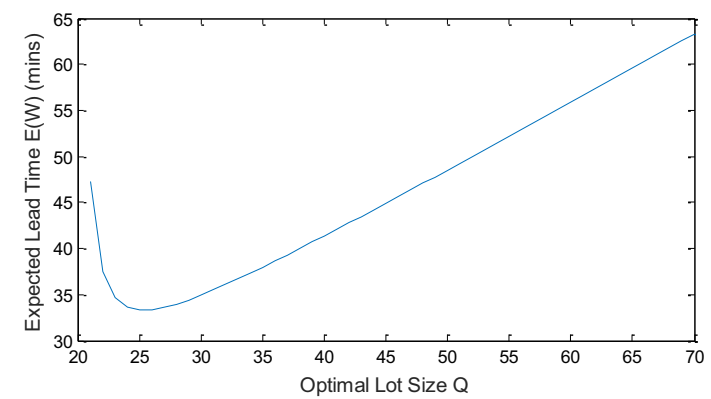

Figure 2. The expected leading time function of lot size

\subsection{Model under carbon constraint}

The carbon cap given by the government is usually for the total amount of annually carbon emission by the company. The manager therefore needs to determine the carbon emission quota released to different departments or production lines based on their carbon emission amounts. To study the influence of carbon cap on the production performance, the carbon emission cap for the proposed production system is set as between 46 and 65 tons to study situations with different carbon constraints.

By changing the carbon emission cap, the lot sizing interval will vary correspondingly, leading to different cases as discussed in Proposition 6. Table 1 shows the lot size interval, optimal lot size and profit of proposed model under the carbon cap constraints with comparison of optimal lot size of benchmark model.

Table 1. Effects of carbon constraint on lot sizing optimisation

\begin{tabular}{|c|c|c|c|c|c|}
\hline $\begin{array}{c}\text { Cap } \\
\mathrm{M} \\
\text { (ton) }\end{array}$ & {$\left[Q^{e, 1}, \mathrm{Q}^{\mathrm{e}, 2}\right]$} & $Q^{*}$ & $\begin{array}{c}\text { Optimal } \\
\text { Lot size } \\
Q\end{array}$ & $\begin{array}{c}\text { Profit } \\
\mathrm{R} \\
(\mathrm{mil})\end{array}$ & $\begin{array}{c}\text { Carbon } \\
\text { emission } \\
\text { (ton) }\end{array}$ \\
\hline 46 & {$[24.09,26.94]$} & 34.95 & 26.94 & 5.06 & 46 \\
\hline 47 & {$[23.12,29.07]$} & 34.95 & 29.07 & 5.28 & 47 \\
\hline 48 & {$[22.67,30.68]$} & 34.95 & 30.68 & 5.38 & 48 \\
\hline 49 & {$[22.33,32.18]$} & 34.95 & 32.18 & 5.44 & 49 \\
\hline 50 & {$[22.09,33.57]$} & 34.95 & 33.57 & 5.47 & 50 \\
\hline 51 & {$[21.90,34.93]$} & 34.95 & 34.93 & 5.48 & 51 \\
\hline 52 & {$[21.75,36.23]$} & 34.95 & 34.95 & 5.48 & 51 \\
\hline 54 & {$[21.51,38.78]$} & 34.95 & 34.95 & 5.48 & 51 \\
\hline 56 & {$[21.34,41.27]$} & 34.95 & 34.95 & 5.48 & 51 \\
\hline 58 & {$[21.20,43.73]$} & 34.95 & 34.95 & 5.48 & 51 \\
\hline 60 & {$[21.09,46.15]$} & 34.95 & 34.95 & 5.48 & 51 \\
\hline 65 & {$[20.03,52.89]$} & 34.95 & 34.95 & 5.48 & 51 \\
\hline
\end{tabular}

Based on the Table 1, the function curves are drawn as below. Fig. 3.1 shows that when the carbon cap is smaller than the carbon emission value of benchmark model ( $M \leq 51$ tons), the carbon emission amount is restricted by the carbon cap and it is always equal to the carbon cap. Fig. 3.2 implies that a smaller lot size leads to lower carbon emission when $M \leq 51$ tons. When $M>51$ tons, the lot size remains at the value that achieve maximal profit. On the other hand, Fig. 3.3 indicates the impact of carbon cap on the profit, in that the profit increases with the increase in carbon cap until it flattens out at $M>51$ tons. Fig. 3.4 illustrate the relationship between the lot size and the profit. A large lot size increases profit but leads to more carbon emission. The case study shows that in response to being imposed of a small carbon cap, a firm can reduce its lot size for production to reduce carbon emission.
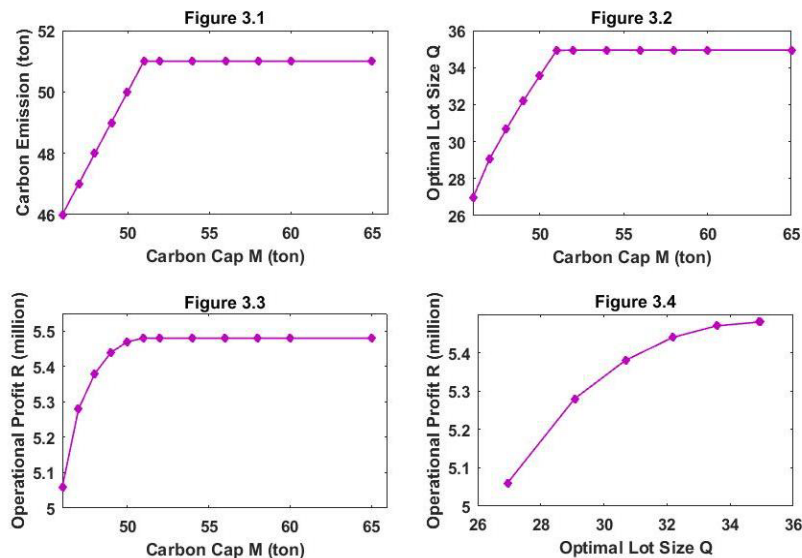

Figure 3. The function curves

\section{Conclusion}

This paper deals with the stochastic lot sizing problem for profit maximization in MTO manufacturing under carbon emission caps. It aims to optimise the lot size for profit maximization while limiting the total carbon emission below the carbon cap. Numerical experiments are carried out to validate the propositions and analytical insights of the model. The results show that a lower carbon cap tends to motivate a company to set small lot sizes, which can reduce carbon emission with slightly decrease in profit. Although sacrifice of short-term profits may be unavoidable, controlling carbon emission help enhance the company's market image and reputation as being socially responsible which would attract more customers who concern about environmental protection. Hence, manufacturers are encouraged to adjust production plans or use new technologies to control carbon emission accordingly.

\section{References}

1. United-Nations, Paris Agreement: Framework Convention on Climate Change, 2 (2015)

2. J. Sarkis, Q. Zhu, and K.-h. Lai, An organizational theoretic review of green supply chain management literature, Int. J. Prod. Econ., 130, pp. 1-15 (2011)

3. M. Brandenburg, K. Govindan, J. Sarkis, and S. Seuring, Quantitative models for sustainable supply 
chain management: Developments and directions, Eur. J. Oper. Res., 233, 299-312 (2014)

4. Accenture, Collaborative Action on Climate Risk-CDP Supply Chain Report (2014)

5. K. Govindan, J. Sarkis, C. J. C. Jabbour, Q. Zhu, and Y. Geng, Eco-efficiency based green supply chain management: Current status and opportunities, Eur. J. Oper. Res., 2, 293-298 (2014)

6. N. Absi, S. Dauzère-Pérès, S. Kedad-Sidhoum, B. Penz, and C. Rapine, Lot sizing with carbon emission constraints, Eur. J. Oper. Res., 227, 55-61 (2013)
7. X. Chen, S. Benjaafar, and A. Elomri, The carbonconstrained EOQ, Oper. Res. Lett., 41.2, 172-179 (2013)

8. M. R. Lambrecht and N. J. Vandaele, A general approximation for the single product lot sizing model with queueing delays, Eur. J. Oper. Res., 95, 73-88 (1996)

9. R. H. Garrison and E. W. Noreen, Managerial Accounting. USA: Irwin McGraw-Hill (2000). 